\title{
FATIGUE LIFE PREDICTION OF UPPER ARM SUSPENSION USING STRAIN LIFE APPROACH.
}

\author{
Submitted on 18/03/2018 - Accepted on 23/12/2018
}

\begin{abstract}
This paper presents the fatigue life behavior of upper arm suspension under cyclic loading. The main objectives are to predict the fatigue life of the component using strain life approach, to identify the critical location and to select the suitable materials for the suspension arm.To conduct this analysis three aluminum alloys were selected for the suspension arm, to do so CAD model of upper arm is designed in Solid Works and imported in a finite element ANSYS code. The upper arm was subjected to constant amplitude loading in z direction and boundary conditions were applied at the end of bushing. Tetrahedral elements gives enhanced results as compared to other types of elements, therefore the elements used in this analysis is (TET 10); the maximum principal stress is considered in the linear static stress analysis and the critical location was considered at node 63754. The finite element model and analysis were performed utilizing the finite element analysis code. Finally, damage is evaluated to the remaining capacity of life and then the stress and strain at the critical region are estimated. From the fatigue analysis Aluminum alloys 7175-T73 and 2014-T6 presents a similar behavior compared to 6061-T6, in this case of study these lather are considered to be the materials of choice to manufacture the suspension arms; but 7175-T73 Aluminum alloys remains the material with a better resistance to fatigue.
\end{abstract}

Keywords: Upper Suspension arm, finite element analysis, constant amplitude loading, strain-life method, critical location.

\section{H KAHOUL ${ }^{1}$ \\ S BELHOUR ${ }^{1}$ \\ A BELLAOUAR ${ }^{2}$}

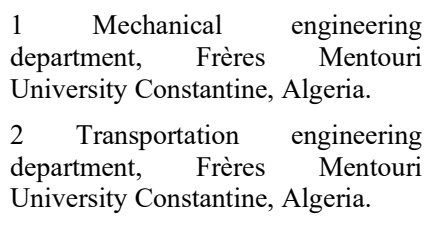

\section{INTRODUCTION}

The suspension system is one of the most important components of vehicle, which directly affects the safety, performance, noise level and style of it. The vehicle suspension system is responsible for driving comfort and safety as the suspension carries the vehicle-body and transmits all forces between body and road [1]. In the automotive industry, the riding comfort and handling qualities of an automobile are greatly affected by the suspension system, in which the suspended portion of the vehicle is attached to the wheels by elastic members in order to cushion the impact of road irregularities. Suspension arm is one of the main components in the suspension systems; it joins the wheel hub to the vehicle frame allowing for a full range of motion while maintaining proper suspension alignment. Uneven tire wear, suspension noise or misalignment, vibrations are the main causes of the failure of the lower suspension arm. Most of the cases the failures are catastrophic in nature as the Finite element method (FEM) gives better visualization of this kind of the failures so FEM analysis of the stress distributions around typical failure initiations sites is essential. Therefore in this paper it is proposed to carry out fatigue analysis of upper suspension arm of light commercial vehicle using FEM.

Fatigue analyses can be performed using either one of the three basic methodologies including the stress-life approach, strain-life approach [2] and crack growth approach. The stress-life method was first applied over a hundred years ago and considers nominal elastic stresses and how they are related to life. This approach to the fatigue analysis of components works well for situations in which only elastic stresses and strains are present however, most components may appear to have nominally cyclic elastic stresses but stress concentrations present in the component may result in local cyclic plastic deformation. Under these conditions, fatigue analysis using the local strain-life method uses the local strains as the governing fatigue parameter and capable of handling significant levels of cyclic plasticity [3].

The strain-life approach can be used proactively for a component during early design stages and the fatigue resistance of metals can be characterized by a strain-life curve see Fig1. The relationship between the total strain amplitude $(\Delta \varepsilon / 2)$ and the reversals to failure (2Nf) can be expressed in Eq. (1) [4-5].

$$
\frac{\Delta \varepsilon}{2}=\frac{\sigma_{f}}{\mathrm{E}}\left(2 \mathrm{~N}_{f}\right)^{b}+\epsilon_{f}\left(2 \mathrm{~N}_{f}\right)^{c}
$$

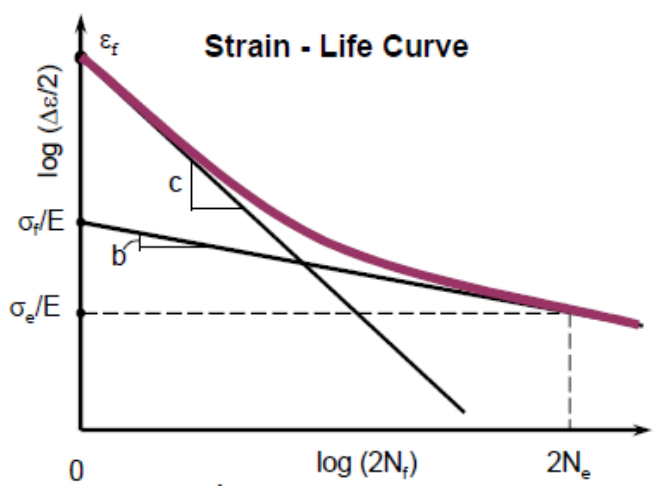

Fig 1. Strain life curve [6]. 
Where $N_{f}$ is the fatigue life, $\sigma_{f}$ is the fatigue strength, $\mathrm{E}$ is the modulus of elasticity, $\mathrm{b}$ is the fatigue strength exponent, $\varepsilon_{f}$ is the fatigue ductility coefficient, and $\mathrm{c}$ is the fatigue ductility exponent. It should be noted that this methodology is based on the fact that plastic deformation is a small fraction of total deformation; this is why this method delivers good estimates in high fatigue cycle regions where elastic deformation controls the processes of fatigue damage. So, this methodology is not unique as a tool for low cycle and high fatigue cycle prediction [7]. The local strain-life approach is preferred if the loading history is irregular and where the mean stress and the load sequence effects are thought to be of importance. The strain-life approach involves the techniques for converting the loading history, geometry and materials properties (monotonic and cyclic) input into a fatigue life prediction. First, the stress and strain at the critical region are estimated then, the crack initiation methods are employed to predict the fatigue life. The simple linear hypothesis proposed by Palmgren [8] and Miner [9] is used to accumulate the fatigue damage. Finally, the damage values for all cycles are summed until a critical damage sum (failure criteria) is reached. The concept of damage represents the state of degradation of the material considered. This state result in a quantitative representation of the endurance of the materials subjected to various loading history; a cumulative damage law is, for its part, a rule for accumulating damage variable $\mathrm{D}$ as for the service life; it is defined by a number of cycles $\mathrm{N}$ which leads to the rupture thus, the application of $\mathrm{n}$ cycles $(\mathrm{n}<\mathrm{N})$ causes a partial deterioration of the part considered for the calculation. The evaluation of the damage, at a given moment, is decisive to evaluate the remaining capacity of life. Fatemi and Yang [10] have documented in the literature more than fifty laws of cumulative damage; the most used today is that of linear damage PalmgrenMiner remains the best compromise between the simplicity of application and the quality of forecasts for long life [11]. The Miner's rule is as follows:

$$
d_{i}=\frac{n_{i}}{N_{I}}
$$

With $\mathrm{n}_{\mathrm{i}}$ number of repetitions of a given cycle (with amplitude or range), $\mathrm{N}_{\mathrm{i}}$ number of repetitions of the same cycle required to declare the failing component $\left(\mathrm{n}_{\mathrm{i}}<\mathrm{N}_{\mathrm{i}}\right)$. For the different cycles of the random solicitation studied, the overall damage is obtained by linear addition of the elementary damages:

$$
\mathrm{D}=\sum_{\mathrm{i}} \mathrm{d}_{\mathrm{i}}=\sum_{\mathrm{i}} \frac{\mathrm{n}_{\mathrm{i}}}{\mathrm{N}_{\mathrm{i}}}
$$

\section{MATERIAL INFORMATION :}

Material model and material properties play an important role in the result of the FEM. The material properties are one of the major inputs which is the definition of how a material behaves under the cyclic loading conditions. The cyclic material properties are used to calculate the elastic-plastic stress-strain response and the rate at which fatigue damage accumulate due to each fatigue cycle. The materials parameters required depend on the analysis methodology being used. The mechanical properties of Materials used in this analysis are shown in Table 1.

\begin{tabular}{|c|c|c|c|}
\hline & $\begin{array}{l}\text { Aluminum } \\
\text { alloy 2014- } \\
\text { T6_125_HF }\end{array}$ & $\begin{array}{l}\text { Aluminum } \\
\text { alloy } \\
\text { 6061- } \\
\text { T6_80_HF }\end{array}$ & $\begin{array}{r}\text { Alumin } \\
\text { alloy } 71 \\
\text { T73_NON }\end{array}$ \\
\hline $\begin{array}{l}\text { Tensile strength, } \\
\text { бUts }(\mathrm{MPa})\end{array}$ & 483 & 340 & 524 \\
\hline $\begin{array}{l}\text { Yield strength, } \sigma_{Y S} \\
(\mathrm{MPa})\end{array}$ & 437 & 313 & 447 \\
\hline $\begin{array}{l}\text { Young's modulus, E } \\
(\mathrm{GPa})\end{array}$ & 72.7 & 72.7 & 71.3 \\
\hline $\begin{array}{c}\text { Fatigue strength } \\
\text { exponent, b }\end{array}$ & -0.12 & $-0,097$ & -0.082 \\
\hline $\begin{array}{c}\text { Fatigue strength }, \sigma_{f} \\
(\mathrm{MPa})\end{array}$ & 976 & 645 & 765 \\
\hline $\begin{array}{c}\text { Fatigue ductility } \\
\text { exponent, c }\end{array}$ & -0.88 & -0.6 & -1.14 \\
\hline $\begin{array}{l}\text { Fatigue ductility } \\
\text { coefficient, } \varepsilon_{\mathrm{f}}\end{array}$ & 0.88 & 0.22 & 6.18 \\
\hline
\end{tabular}

Table 1: Materials properties of Aluminum alloys

\section{MODEL DESCRIPTION}

Vehicle suspension is a mechanism locating between the sprung mass (vehicle body) and the unsprung masses (wheels) of the vehicle. The suspension provides forces between these two masses of the vehicle according to certain state variables of the vehicle. A good car suspension system should have satisfactory road holding ability, while still providing comfort when riding over bumps and holes in the road. A simple three-dimensional model of suspension arm was modeling by using Solid Works software then imported to Ansys finite element code. Fig 2. shows the structural model [12].The weight is $1.19 \mathrm{~kg}$ and the size is $320 \mathrm{~mm} \mathrm{x}$ $260 \mathrm{~mm} \times 68 \mathrm{~mm}[\mathbf{1 3}, 14$ and $\mathbf{1 5}]$.

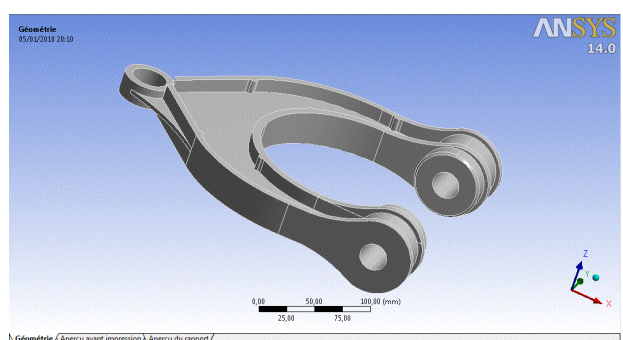

Fig 2. Three-dimensional FE model 


\section{MESH GENERATION :}

In this analysis mesh generation is auto generation by the ANSYS software, after that sizing of $3 \mathrm{~mm}$ was given to the suspension arm. Tetrahedral 10-noded elements were used to mesh the upper suspension arm, see Fig 3.

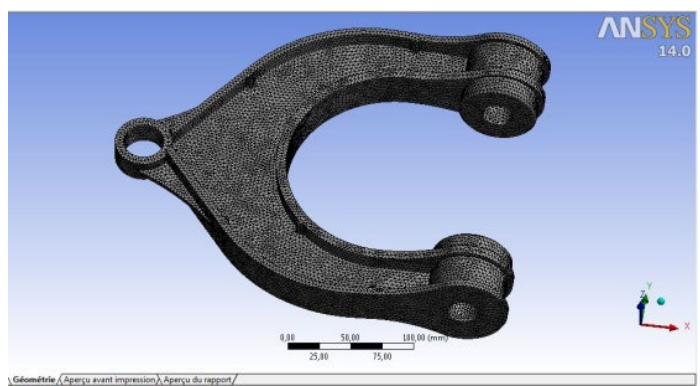

Fig 3. Mesh model with tetrahedral element (TET 10)

\section{LOADING}

We consider vertical force $2500 \mathrm{~N}$ is loaded with constant amplitude in $\mathrm{Z}$ direction [16] applied at the end of the bushing that connected to the tire. The other two bushing that connected to the body of the car are constraint. The threedimensional FE model, loading and constraints of suspension arm is shown see Fig4. [17].

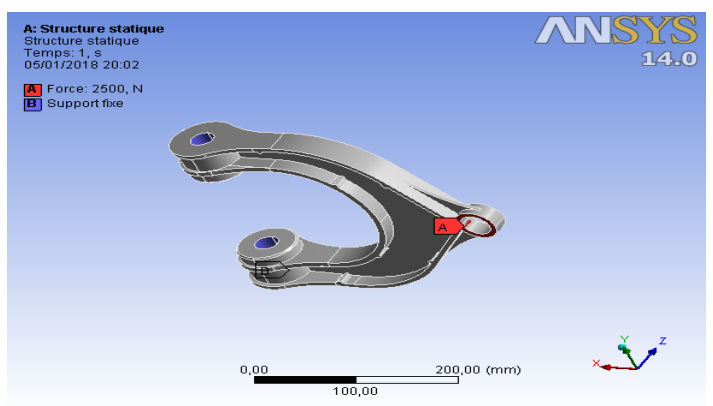

Fig 4. Boundary conditions and force loading

Loading is of constant amplitude because only 1 set of finite element stress results along with a loading ratio is required to calculate the alternating and mean stress. The loading ratio is defined as the ratio of the second load to the first load

$$
R=\sigma_{\min } / \sigma_{\max }
$$

In this study constant amplitude loading is fully reversed (apply a load then apply an equal and opposite load; a load ratio of -1).

\section{RESULTS AND DISCUSSION}

In this analysis we use Ansys software based on (FEM), it is known for its high performance, quality and ability to solve all kinds of challenging simulations.
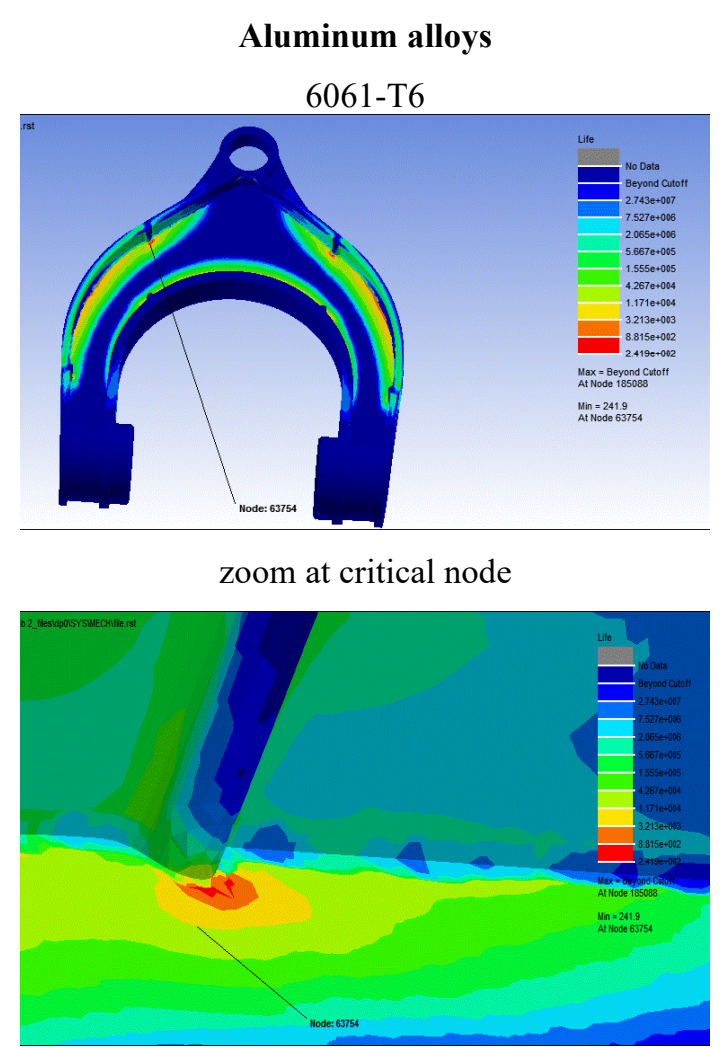

2014-T6

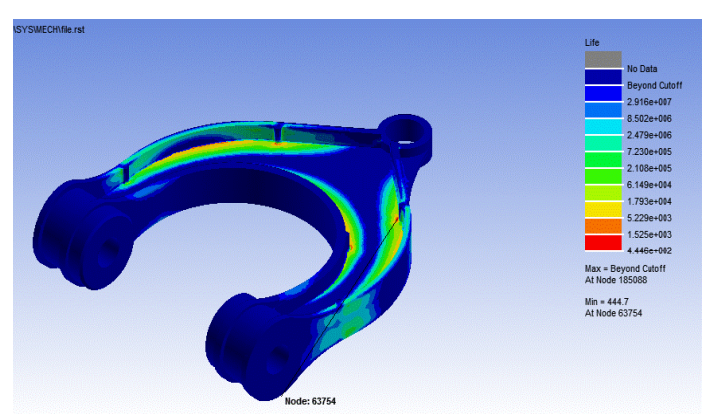

7175-T7

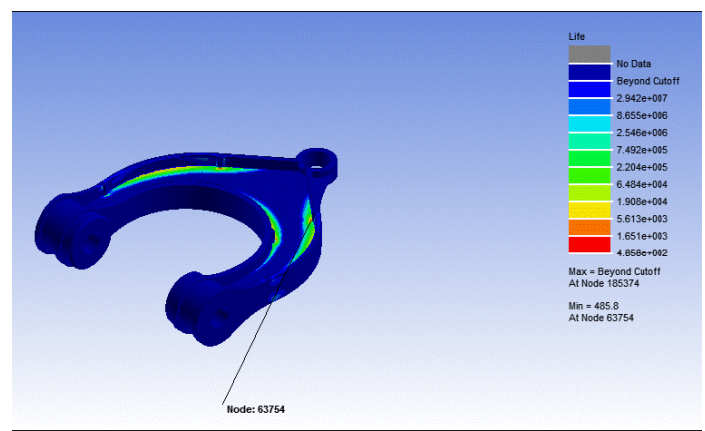

Fig 5. Predicted life contour .

Fig 5. shows predicted life contour plotted for the three aluminum alloys; we see that 6061-T6 aluminum alloys presents the shortest life at node 63754 . 

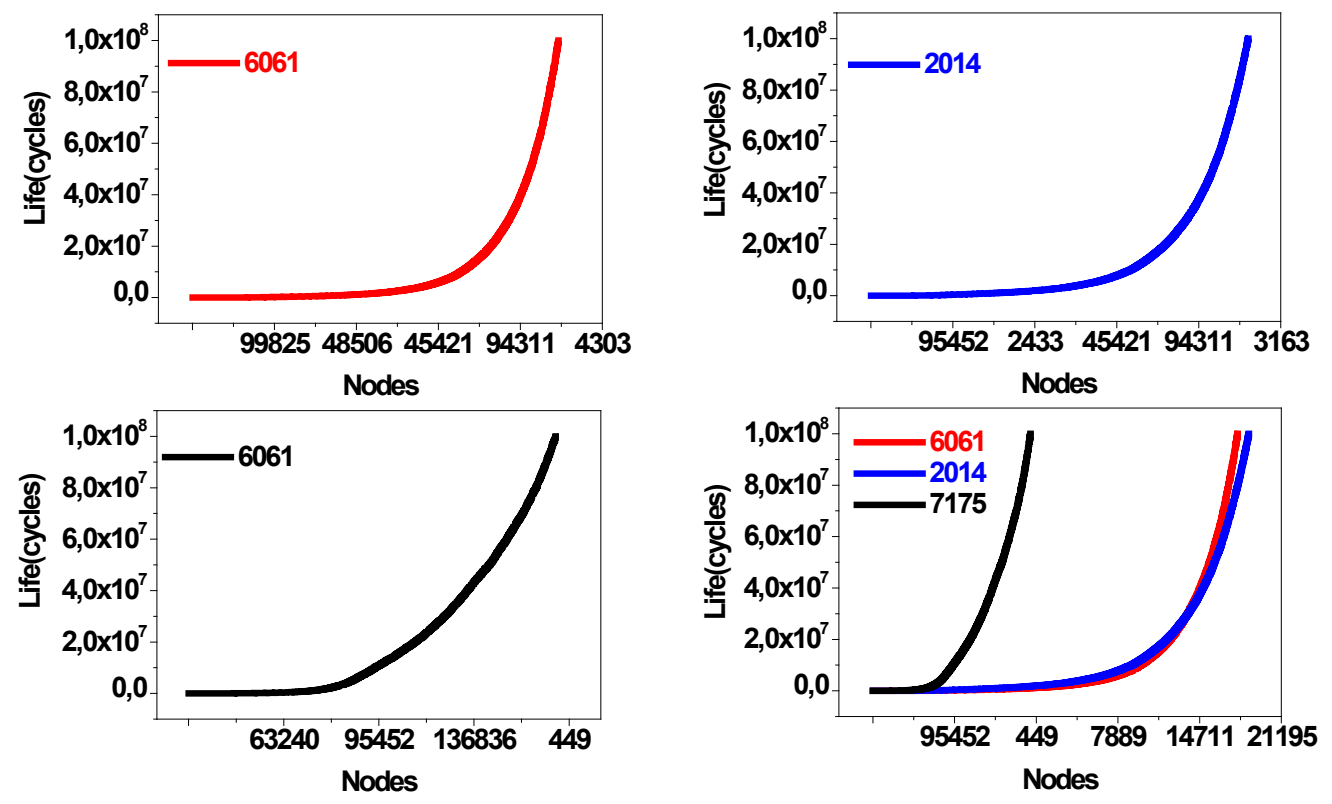

a) At all nodes

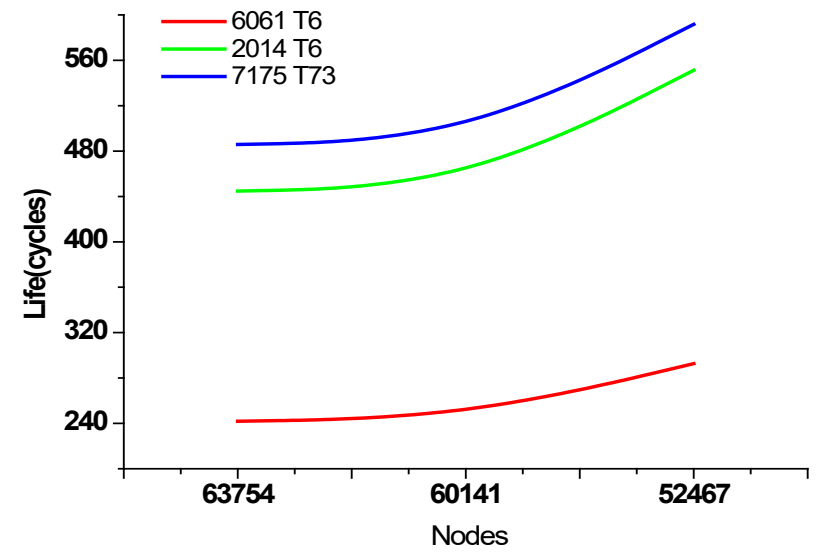

b) At 10 hot spot nodes

Fig 6. Composite plot for three materials Predicted life-nodes curves.

Fig 6. shows the increase of life a) at all nodes and , b) at 10 hot spot nodes. We see clearly that the critical area is at node 63754. Among the three studied materials, 6061-T6 shows the shortest fatigue life ( 241.9 cycles) due to the development of stress concentration near singularitie which led of a large deformation.

Fig 7. shows damage contour plotted for the same materials ; the higher damage corresponds to 6061-T6 aluminum alloy since it has the shortest life.
6061-T6

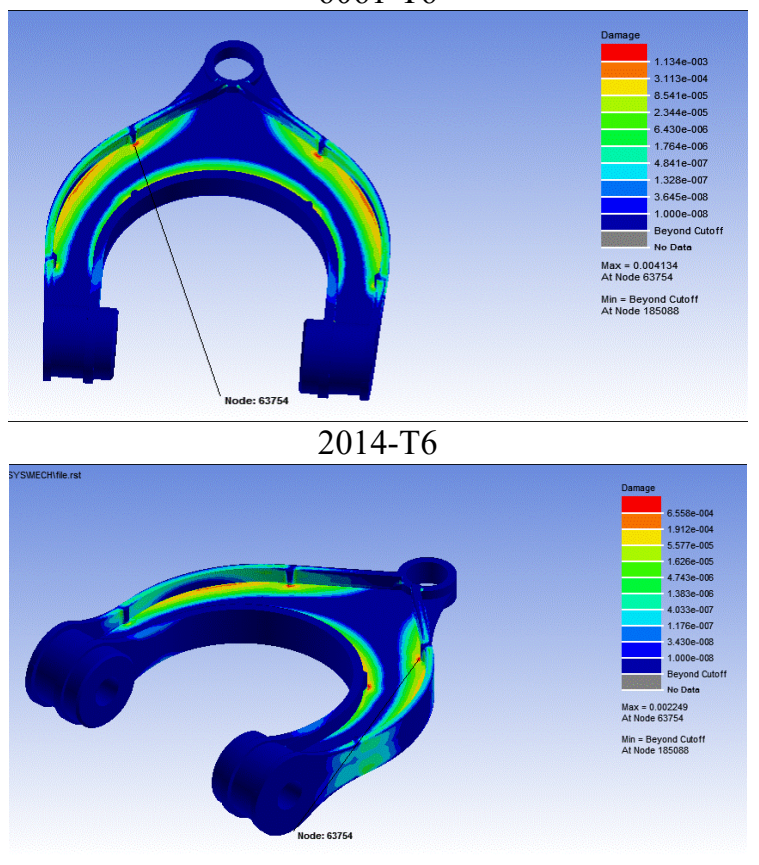

7175-T73

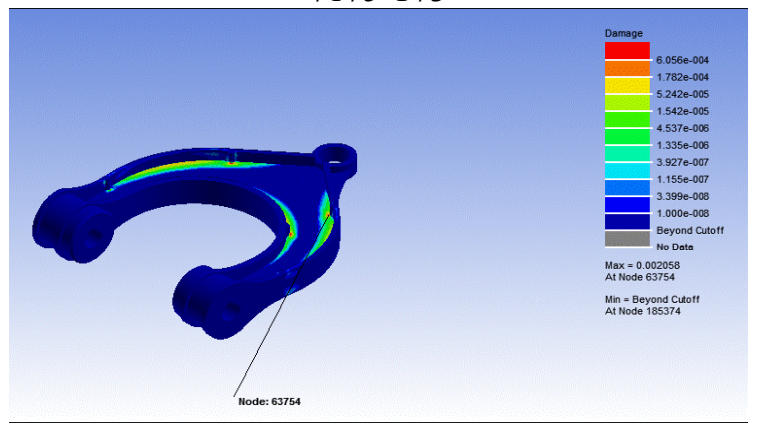

Fig 7. Damage contour plotted. 

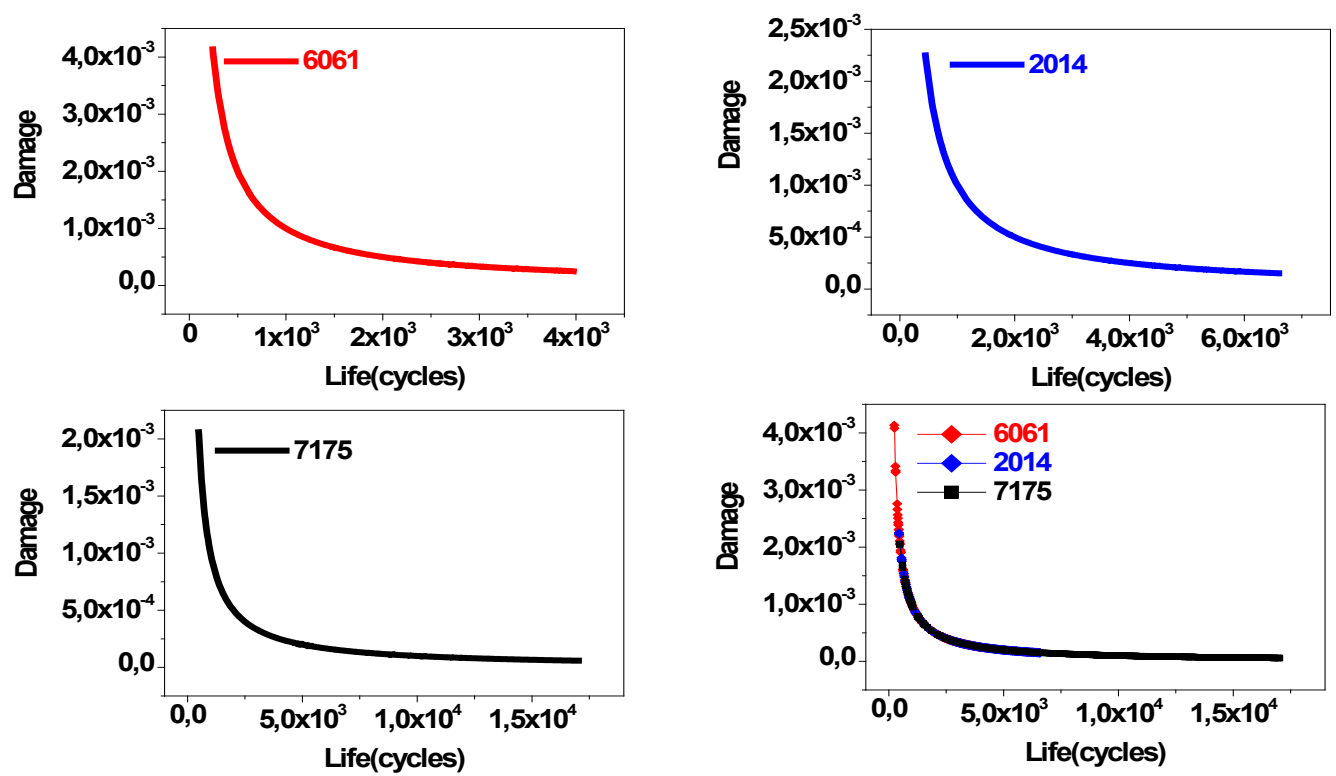

a) At all nodes

b) At 10 hot spot nodes

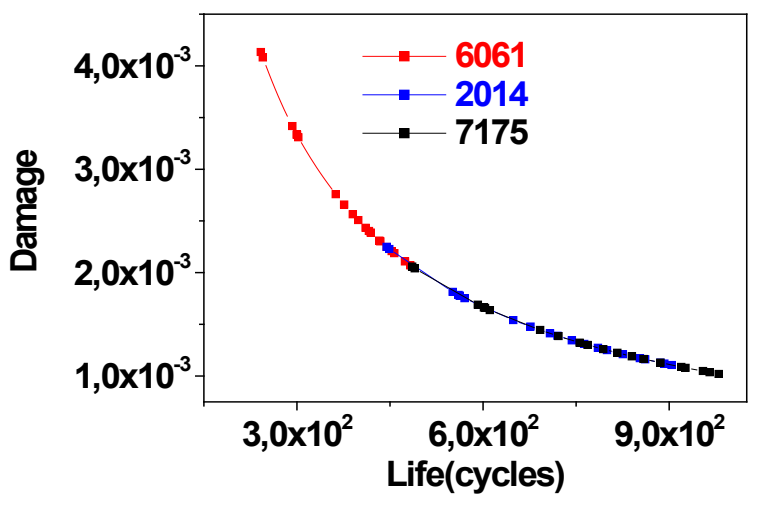

Fig 8. Composite plot of three materials Damage-Life curves

Fig 8. shows damage according to the number of cycles which decreases with increasing cycles. We note that for cycles less than 500 cycles the damage is more important. The higher damage of 4.13 E-3 at node 63754 corresponding to 241 cycles is that of 6061-T6. The damage depends on strain rate. For life less than 500 cycles the deformation is mainly plastic,whereas for life larger than 500 cycles the deformation is mainly elastic.

Fig. 9 shows strain contour plotted for the three aluminum alloys ; we see clearly that the maximum strain observed at node 63754 is for 6061-T6.
6061-T6
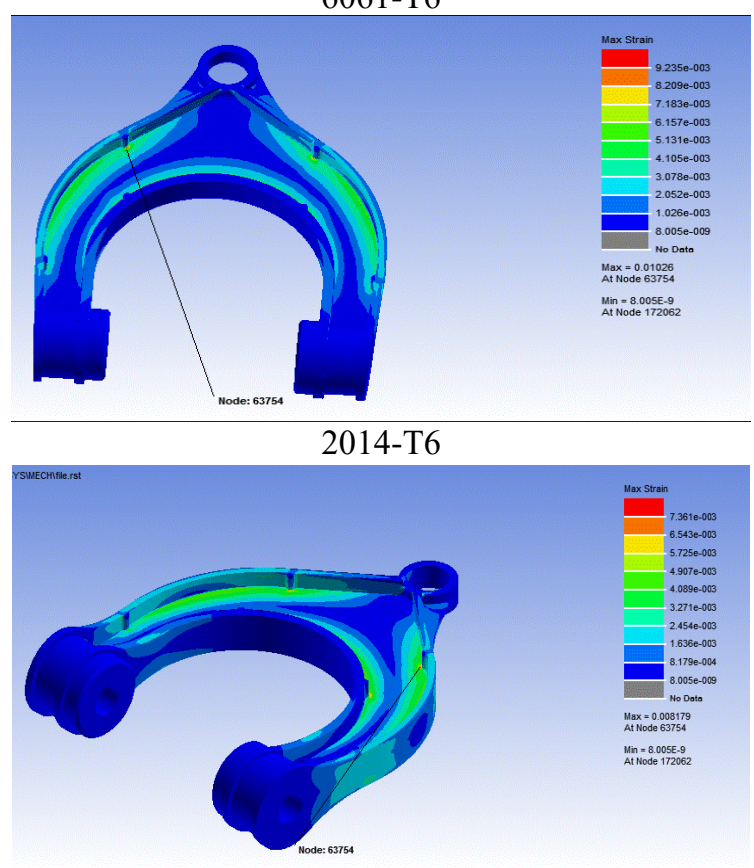

7175-T73

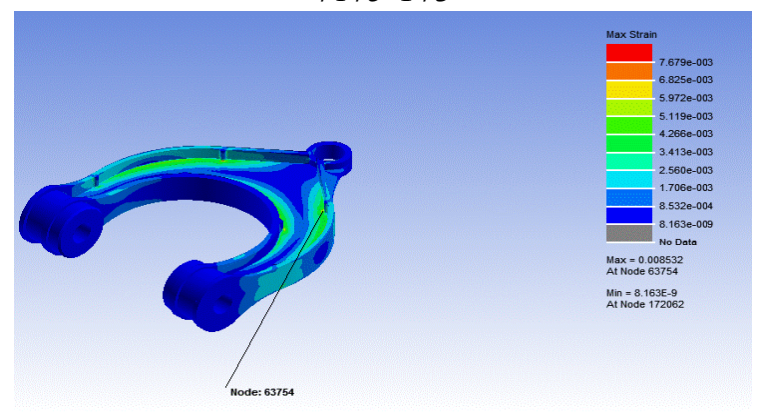

Fig 9. Strain contour plotted 

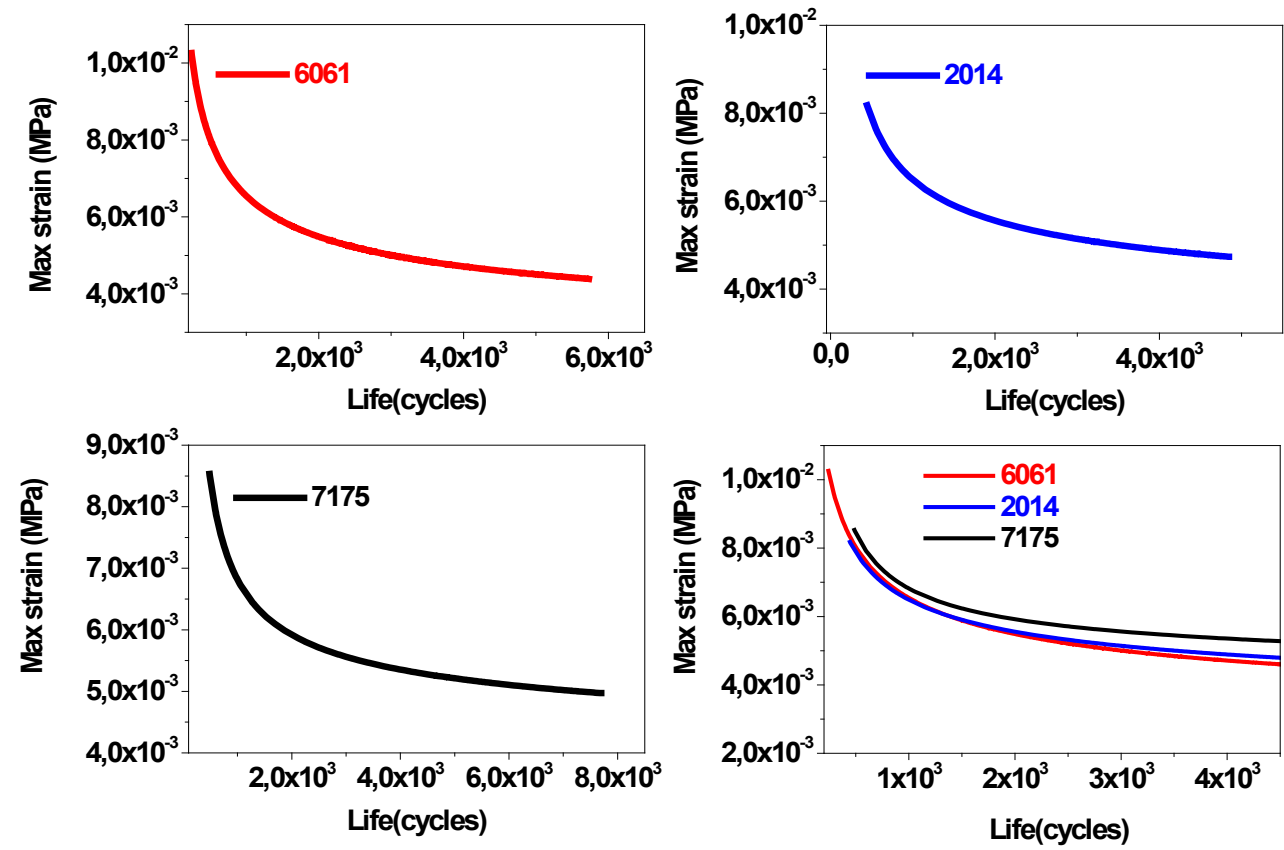

a) at all nodes

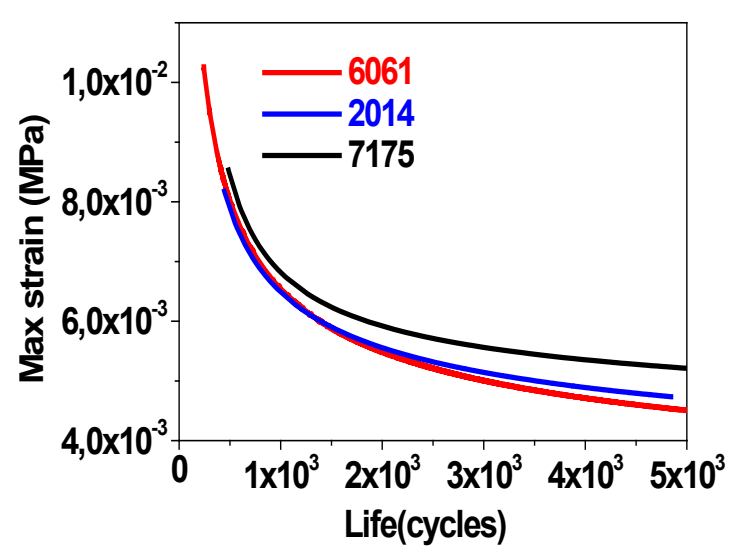

b) at 10 hot spot nodes

Fig 10. Composite plot of three materials Stress-Life curves

Fig 10. presents graph of strain according to the number of cycles; this graph shows that the strain decrease when the predicted life increases; the max strain observed for 6061T6 is 10.26 E-3 at critical node which correspond to a minimum life of 241.9 cycles.

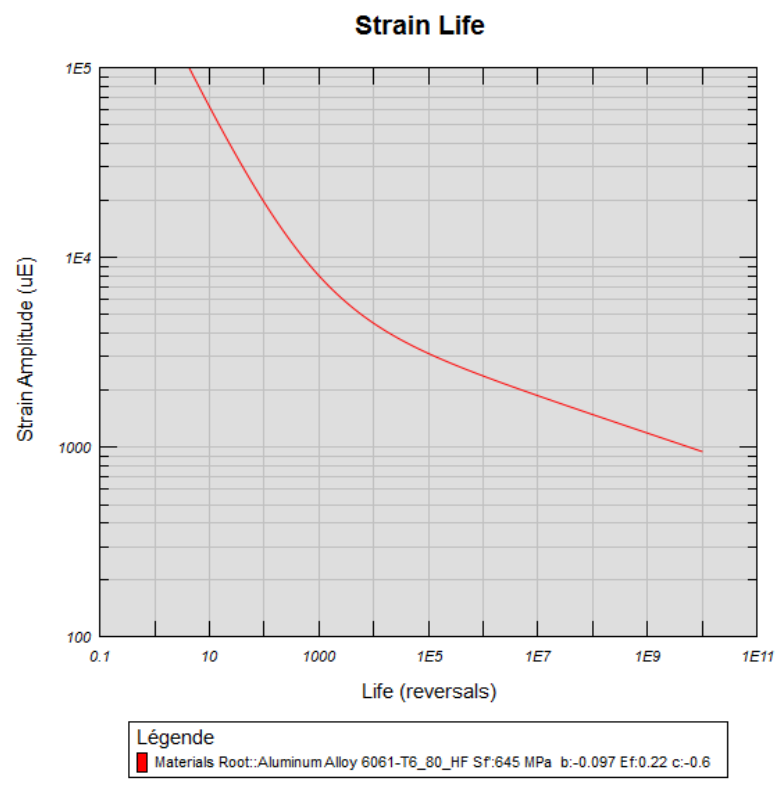

a) 6061 


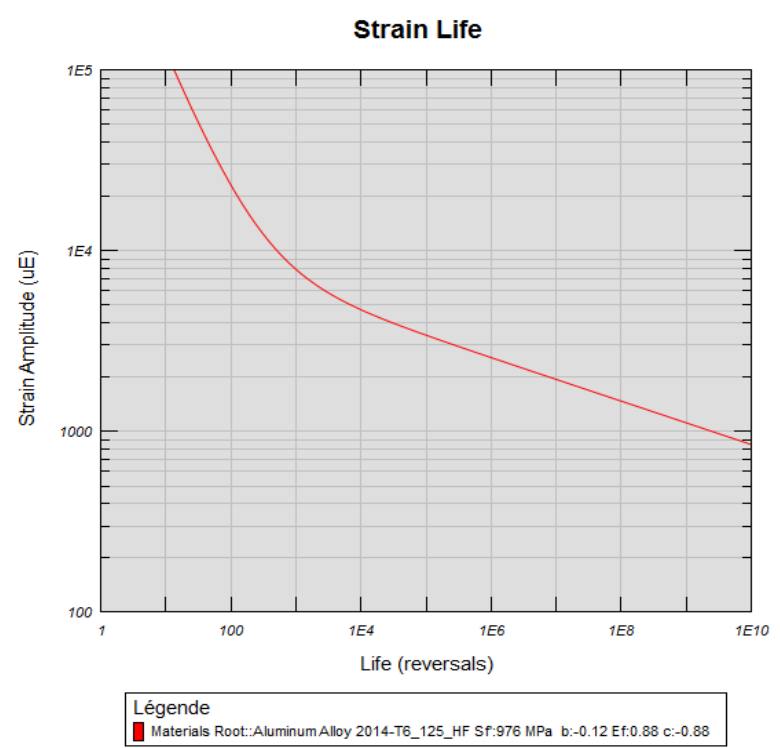

b) 2014

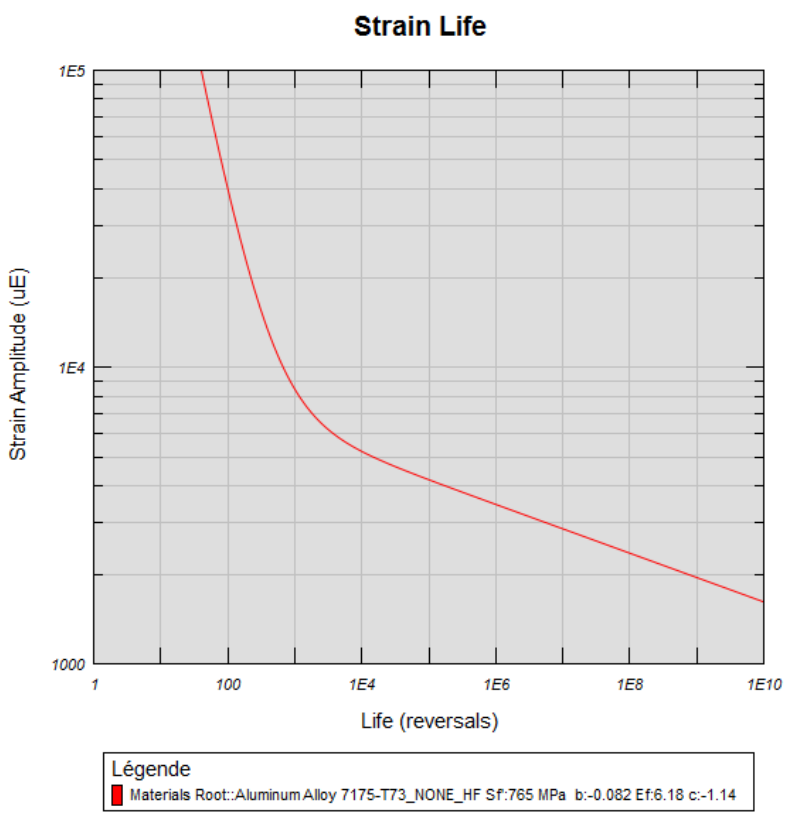

c) 7175

Fig 11. Strain amplitude vs life [2].

Fig 11. shows results tests carried out on three aluminum alloys ; it is clear that the material with the shortest life is 6061-T6 which confirms the appearance of the curves drawn in Fig.10 from the simulation.
6061-T6

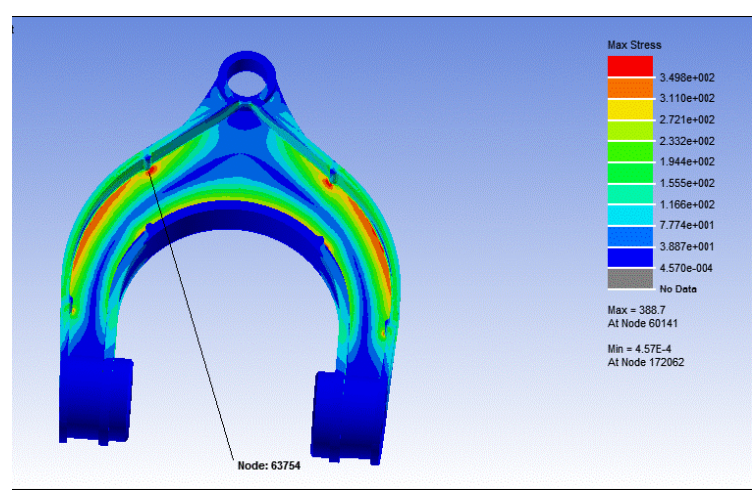

2014-T6

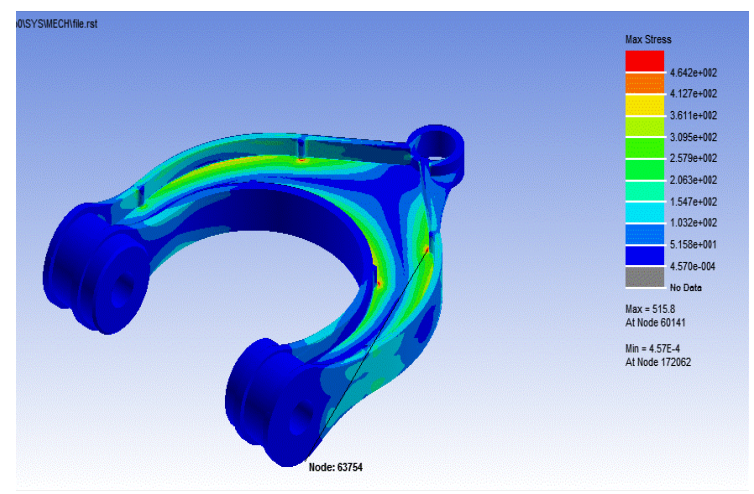

7175-T73

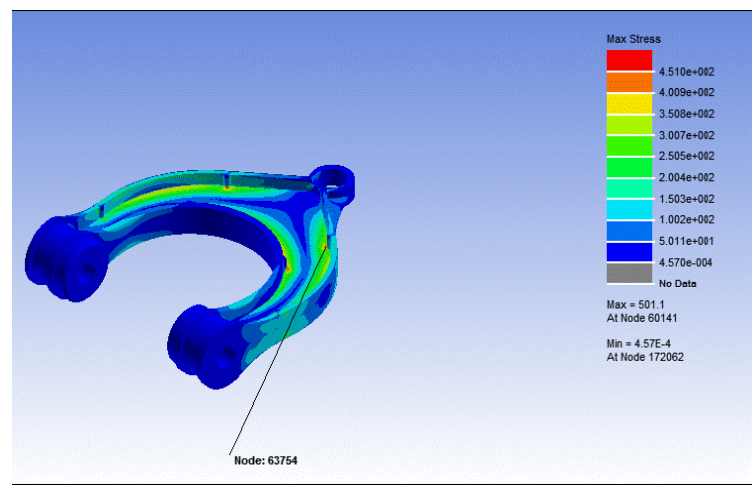

Fig 12. Stress contour plotted. 

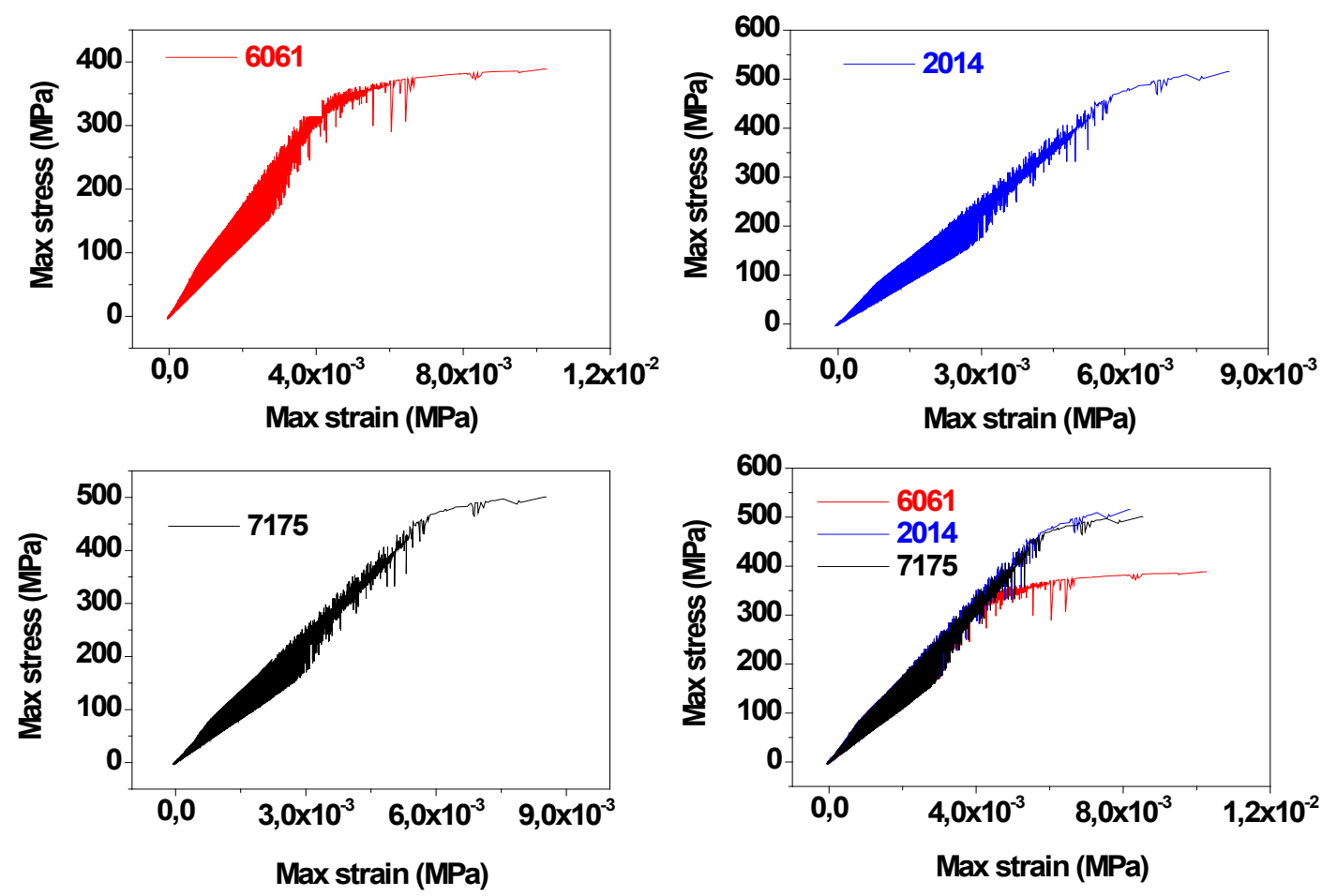

Fig13. Stress amplitude vs. Strain amplitude

Fig 12. shows stress contour plotted for the three materials however Fig 13. shows the evolution of stress according to deformation, we note that for the same loading the levels of constraints and deformations reached for the three materials are not the same, with small difference for 7175 and 2014; however the largest deformation reached is that of 6061 (10.26 E-3) at the critical node 63754 it corresponds to the smallest constraint $(388.6 \mathrm{MPa})$. We also note that the stress levels reached at critical node for three materials exceed their tensile strength which results in elastoplastic behavior of the latter.

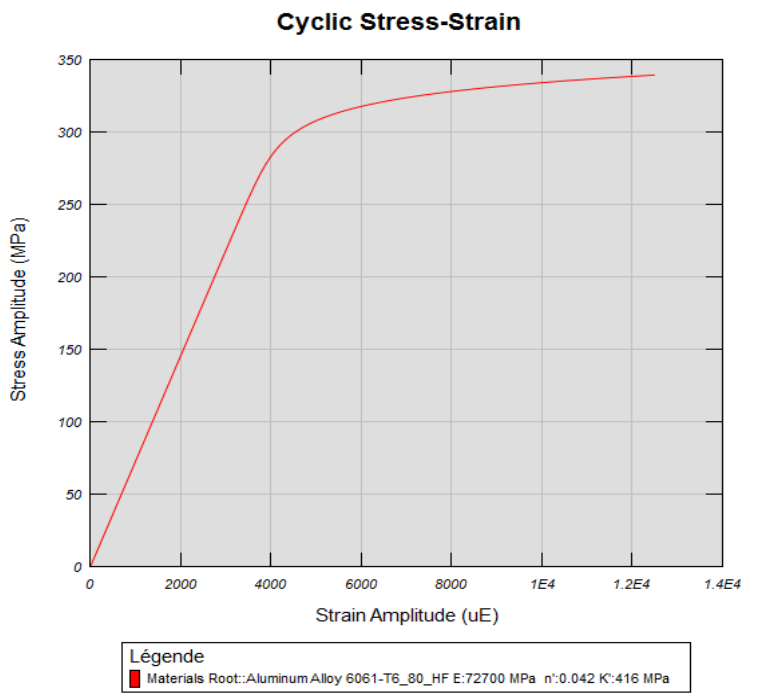

a) 6061

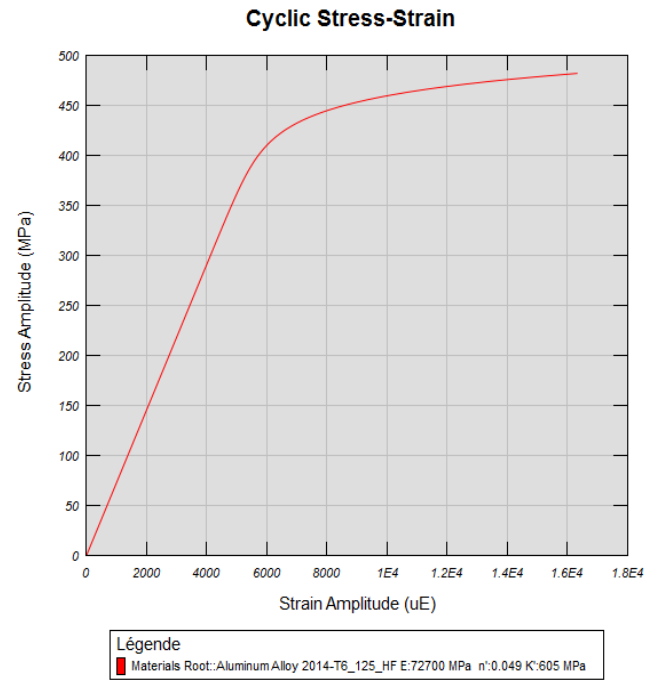

b) 2014 


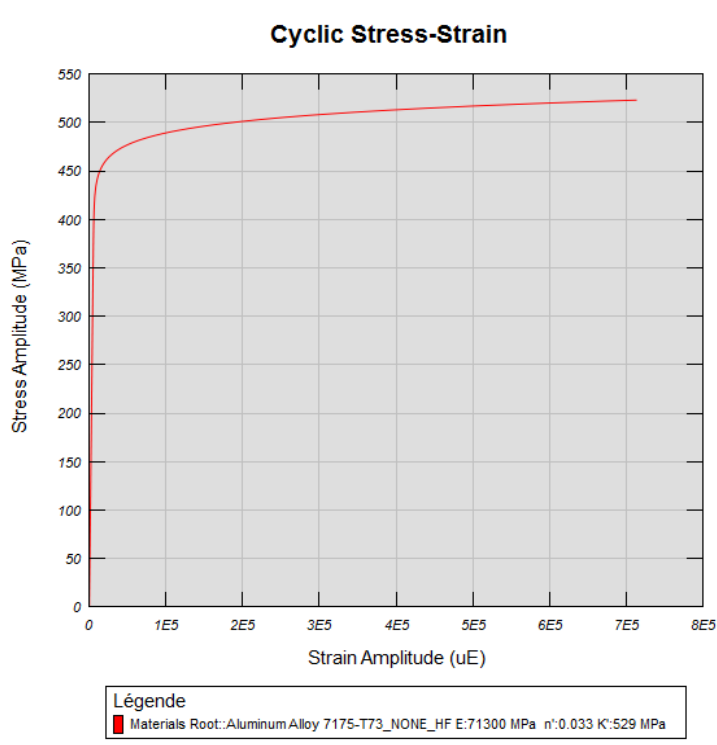

c) 7175

Fig14. Tests stress vs. strain for three materials [2].

Fig 14. shows the stress-strain tests results obtained for the three materials it is clear that there is a correlation between these graphs and the results obtained by simulation. The table 2 summarize the results of the fatigue analysis of the upper arm suspension.

Table 2 Fatigue analysis results for the three materials

\begin{tabular}{ccccc}
\hline & Life cycles & Damage & $\begin{array}{c}\text { Max } \\
\text { stress } \\
\text { MPa }\end{array}$ & $\begin{array}{c}\text { Max } \\
\text { strain }\end{array}$ \\
\hline $\begin{array}{c}\text { 6061- } \\
\text { T6_80_HF }\end{array}$ & 241.9 & $4.13 \mathrm{E}-3$ & 388,6 & $10.26 \mathrm{E}-3$ \\
\hline $\begin{array}{c}\text { 2014- } \\
\text { T6 125_HF }\end{array}$ & 444.7 & $2.24 \mathrm{E}-3$ & 515.8 & $8.17 \mathrm{E}-3$ \\
\hline $\begin{array}{c}\text { 7175- } \\
\text { T73_NONE_HF }\end{array}$ & 485.8 & $2.05 \mathrm{E}-3$ & 501.1 & $8.53 \mathrm{E}-3$ \\
\hline
\end{tabular}

Table 2. shows the results obtained from a fatigue life analysis conducted for three aluminum alloys with different mechanical properties. For 7175-T73 and 2014-T6, the stress values gives almost similar deformations as well as the resulting damage, which explains the similarity of the behavior. The maximum stresses obtained are $515.8 \mathrm{MPa}$ and 501.1 MPa respectively exceeding their tensile strength $\sigma_{\text {UTS }}(483 \mathrm{MPa}$ and $524 \mathrm{MPa}$ ), where the deformations values are of the order of 8.17 E-3 and 8.53 E-3 at node 63754 , we can notice that for approximatively the same range of stress gives the same life and strain . We can also see that the damage caused in the first material (2014T6_125_HF) is slightly higher than in the second one (7175-T73_NONE_HF), a large deformation led to a small damage against a small deformation led to a great damage. However for 6061-T6 for the same loading the level of stress is the smallest with a value of ( $388.6 \mathrm{MPa})$, as well as the deformation is (10.26 E-3) and damage rate is the greatest one (4.13 E-3).

\section{CONCLUSION}

In this study a strain-life approach based on finite element of the fatigue life prediction of a upper arm suspension is presented. The calculation is carried out using Ansys nCode Design Life, one of the leading commercial durability software tools worldwide .Three materials were used to conduct this analysis. Hot spot detection is used to identify the critical areas of the model, 10 most damaged areas are identified, highlighting the worst node in each area. The result of the fatigue analysis based on strain life approch is a life and damage contours plotted for three aluminum alloys, life and damage values are calculated for every node and the red color indicates the minimum life and the maximum damage at critical areas in the component. We see clearly the decrease in life when damage increase. Also the maximum values of stress and strain in each node are évaluated. Finally the fatigue life analysis is focused on node 63754 where there is a local accent constraint near a singularity. This study highlight the influence of the singularities on the behavior of the upper arm. The comparison of the fatigue behavior for the three materials showed the similarity of the behavior between 2014 and 7175 because their fatigue lifes are close as well as the deformations resulting. However for 6061 the deformation obtained is greater which led to a smaller life of around $50 \%$ compared to the two others.

This study shows that 7175-T73 and 2014-T6 aluminum alloys suspension arm presents a better resistance to fatigue and higher life compared to 6061-T6 aluminum alloys. Thus, these lather are considered to be the materials of choice in this case of study.this comparison allows us to made it possible to understand their performances and the mechanisms of damage within the suspension arm as well as the values of the fatigue life obtained.

From this study we could notice that:

- At large strains or short lives, the plastic strain component is predominant, and at small strains or longer lives the elastic strain component is predominant. - At larger strains, increased life is dependent more on ductility, while at smaller strains longer life is obtained from higher strength materials.

- Most fatigue failures begin at local discontinuities where local plasticity exists and crack nucleation and growth are governed by local plasticity at the notch tip.

- The optimum overall strain-life behavior is for tough metals, which are materials with good combinations of strength and ductility larger strains. 


\section{REFERENCES}

[1]. Shaikh Ateekh Abdul Naeem, P. V. Jagtap. Analysis of Upper Control Arm for finding optimized model using FEA and Experimentation. Imperial Journal of Interdisciplinary Research (IJIR) Vol-3, Issue-3, 2017.

[2]. M. M. Rahman,K. Kadirgama,M. M. Noor,M. R. M. Rejab,S. A. Kesulai. "Fatigue Life Prediction of lower suspension arm using strain-life approach". European journal of scientific research Vol.30 No.3 (2009), pp.437450.

[3]. NCode Design Life User Guide, HBM United Kingdom Limited 2012.

[4]. Morrow, J. 1968. Fatigue Design Handbook: Advances in Engineering. Warendale, PA: SAE, 21-29.

[5]. Smith, K.N., Watson, P. and Topper, T.H. 1970. A stress-strain functions for the fatigue on materials. Journal of Materials. 5 (4): 767-78.

[6].https://www.efatigue.com/training/Strain_Life_Method. $p d f$.

[7]. Abdel Hamid Saoudi, "Prédiction de la rupture par fatigue dans les pièces automobiles en alliages aluminium" .Thèse de doctorat, 2008, Université du Québec à Chicoutimi.

[8]. Palmgren, A., 1924. Durability of ball bearings. ZVDI, 68(14): 339-341.M.

[9]. Miner, A., 1945. Cumulative damage in fatigue. Journal of Applied Mechanics. 12: 159-164.
[10]. Fatemi (A.) et Yang (L.). - Cumulative fatigue damage and life prediction theories : a survey of the state of the art for homogeneous materials. Int J Fatigue, 20(1), p. 9-34 (1998).

[11]. BANVILlet (A.). "Prévision de durée de vie en fatigue multiaxiale sous chargements réels : vers des essais accélérés". Thèse de doctorat $\mathrm{N}^{\circ}$ 2001-17 (274 p.), ENSAM Bordeaux,France (2001).

[12]. Journal of Advanced Science and Engineering Research 1 (2011) 42-52.

[13]. T. Lindby and J.L.T. Santos; Shape optimization of three-dimensional shell structures with the shape parameterization of a CAD system, (1999), Page 6.2.

[14]. J. E. Shigley, C. R. Mischke, McGraw Hill; Mechanical Engineering Design, 6 edition, (2000).

[15]. Paul Haney; Basic Vehicle Dynamics, (1999), Page 22.

[16]. Jagwinder Singh, Siddhartha Saha . "Static structural analysis of suspension arm using finite element method": IJRET-International Journal of Research in Engineering and Technology eISSN: 2319-1163 | pISSN: 2321-7308.

[17]. Savan Thacker1 and Antriksh Bhatt2. "Design and Analysis Double Wishbone Suspension System using Finite Element Analysis". IJSRD - International Journal for Scientific Research \& Development| Vol. 2, Issue 09, 2014 | ISSN (online): 2321-0613. 